Published in final edited form as:

Schizophr Res. 2014 August ; 157(0): 33-39. doi:10.1016/j.schres.2014.04.039.

\title{
Functioning in First-Episode Schizophrenia: MATRICS Consensus Cognitive Battery (MCCB) Profile of Impairment
}

\author{
A. McCleery ${ }^{1,{ }^{*}}$, J. Ventura ${ }^{1}$, R. S. Kern ${ }^{1,2}$, K. L. Subotnik ${ }^{1}$, D. Gretchen-Doorly ${ }^{1}$, M. F. \\ Green $^{1,2}$, G. S. Hellemann ${ }^{1}$, and K. H. Nuechterlein ${ }^{1,3}$ \\ ${ }^{1}$ Semel Institute for Neuroscience and Human Behavior, Department of Psychiatry and \\ Biobehavioral Sciences, David Geffen School of Medicine, UCLA, Los Angeles, CA \\ 2VISN 22 Mental Illness Research, Education, and Clinical Center (MIRECC), Greater Los \\ Angeles VA Healthcare System, Los Angeles, CA \\ ${ }^{3}$ Department of Psychology, UCLA, Los Angeles, CA
}

\begin{abstract}
Background-Although many studies have assessed cognitive functioning in first-episode schizophrenia (FESz), the pattern and severity of impairment across cognitive domains remains unclear. Moreover, few studies have directly compared the pattern of cognitive performance between FESz and chronic schizophrenia (CSz). In this study we examined the cognitive
\end{abstract}

(C) 2014 Elsevier B.V. All rights reserved.

"Corresponding Author: Amanda McCleery, Ph.D., UCLA Semel Institute for Neuroscience and Human Behavior, Department of Psychiatry, David Geffen School of Medicine, 300 Medical Plaza, Room 2213, Los Angeles CA 90095, Tel: +1-310-206-8979, Fax: +1-310-206-3651, amccleery@mednet.ucla.edu.

Contributors

K.H. Nuechterlein, J. Ventura, K.L. Subotnik, and D. Gretchen-Doorly designed the study and wrote the FESz protocol, while M.F. Green, K.H. Nuechterlein, and R.S. Kern designed the MATRICS PASS protocol. A. McCleery and K.H. Nuechterlein managed the literature searches and analyses. A. McCleery and G.S. Hellemann undertook the statistical analysis, and A. McCleery wrote the first draft of the manuscript. All authors contributed to and have approved the final manuscript.

Author Disclosure

A. McCleery is supported by the Canadian Institutes of Health Research fellowship award. FESz subject recruitment and data collection were supported by NIMH research grant MH037705 (K.H Nuechterlein, PI) and Center grant MH066086 (K.H. Nuechterlein, PI). CSz and NP subject recruitment and data collection were supported by Contract N01MH22006 from the NIMH to the University of California, Los Angeles (S. Marder, PI; M.F. Green, Co-PI; W. Fenton, Project Officer).

Conflict of Interest

M.F. Green and K.H. Nuechterlein are officers within MATRICS Assessment, Inc., the publisher of the MCCB, but do not receive any financial remuneration for their respective roles. R.S. Kern is an officer for MATRICS Assessment, Inc. and receives financial compensation for his role within the non-profit organization. K.H. Nuechterlein has received unrelated research grants from Janssen Scientific Affairs, Genentech, and Posit Science and has been a consultant to Otsuka and Genentech. J. Ventura has received funding from Janssen Scientific Affairs, LLC, Brain Plasticity, Inc., and Genentech, Inc. He has served as a consultant to Brain Plasticity, Inc., and Boehringer-Ingelheim GmbH. K.L. Subotnik and D. Gretchen-Doorly have received research funding from Janssen Scientific Affairs, LLC, and Genentech, Inc, through grants to K.H. Nuechterlein and J. Ventura. K.L. Subotnik is a consultant to Otsuka America Pharmaceutical, Inc. M.F. Green has been a consultant to AbbVie, Biogen, DSP, and Roche, and he is on the scientific advisory board of Mnemosyne. He has received research funds from Amgen. All other authors declare they have no conflicts of interest.

Publisher's Disclaimer: This is a PDF file of an unedited manuscript that has been accepted for publication. As a service to our customers we are providing this early version of the manuscript. The manuscript will undergo copyediting, typesetting, and review of the resulting proof before it is published in its final citable form. Please note that during the production process errors may be discovered which could affect the content, and all legal disclaimers that apply to the journal pertain. 
impairment profile in FESz using a standardized neurocognitive battery (MATRICS Consensus Cognitive Battery; MCCB).

Methods-MCCB data were compared from 105 FESz patients, $176 \mathrm{CSz}$ patients and 300 nonpsychiatric (NP) participants. Mixed models analysis evaluated group differences in MCCB profiles and relative strengths and weaknesses in the MCCB profiles of patients. Clinical implications of MCCB performance were also examined; we compared the proportion of participants from each group who exhibited clinically-significant global cognitive impairment based on the MCCB Overall Composite score.

Results-FESz and CSz showed impaired performance across all MCCB domains relative to NP. With the exception of relative preservation of working memory and social cognition in FESz, the MCCB domain scores were similar in FESz and CSz. The distribution of impairment on the Overall Composite score did not significantly differ between FESz and CSz; compared to NP, both patient groups were overrepresented in moderate and severe impairment categories.

Conclusion-The pattern, magnitude, and distribution of severity of impairment in FESz were similar to that observed in CSz. However, early in the illness there may be relative sparing of working memory and social cognition.

\section{Keywords}

MCCB; first-episode schizophrenia; cognition; profile analysis; first episode schizophrenia

\section{Introduction}

Marked cognitive impairment is a core, enduring feature of schizophrenia, prompting some researchers to posit that the illness can be conceptualized as primarily a disorder of cognition (Green and Nuechterlein, 1999; Rund, 1998). Among patients with chronic schizophrenia (CSz), cognitive impairment is diffuse and pervasive, with deficits typically 1 to 2 standard deviations below non-psychiatric control samples across various cognitive domains (Gold, 2004; Green, 2006; Heinrichs and Zakzanis, 1998). Cognitive impairment appears to be a relatively stable feature of schizophrenia (Barder et al., 2013b; Hoff et al., 2005), even across acute vs. remitted states (Nuechterlein et al., 1992), with limited response to antipsychotic treatment (Keefe et al., 2007; Rund, 1998). Cognitive impairment is present in first-episode schizophrenia (FESz; (Addington and Addington, 2002; Barder et al., 2013a; Gold et al., 1999; Hoff et al., 1999; Mohamed et al., 1999), and likely precedes the onset of illness in an attenuated form (Cornblatt et al., 1999; Hawkins et al., 2004; Lencz et al., 2006; Lewandowski et al., 2011; Seidman et al., 2010; Simon et al., 2007). However, the findings have been mixed regarding the magnitude of cognitive impairment in FESz compared to $\mathrm{CSz}$, with some studies reporting negligible differences between FESz and CSz (e.g., (Hoff et al., 1992), and others reporting less impairment in FESz relative to CSz, at least on some cognitive tests (e.g., (Addington and Addington, 2002; Albus et al., 1996; Braw et al., 2008; Saykin et al., 1994; Townsend and Norman, 2004). Hence, the pattern and severity of impairment in FESz across cognitive domains remains unclear.

A meta-analysis of 43 studies of cognition in FESz (Mesholam-Gately et al., 2009) provided strong evidence for notable impairment across all cognitive domains, with medium to large 
mean effect sizes on par with those reported in CSz (Heinrichs and Zakzanis, 1998).

Impairment was most pronounced in immediate verbal memory and processing speed, in addition to the global impairment observed in schizophrenia. Indeed, a selective deficit of verbal memory and processing speed has been reported elsewhere in the schizophrenia literature (e.g., (Dickinson et al., 2008; Gonzalez-Blanch et al., 2010). The meta-analysis noted significant heterogeneity of effect sizes within cognitive domains and between studies, likely due to methodological variations across studies, such as differences in the operational definition of FESz, properties of the patient samples (e.g., diagnoses, demographic variables), medications, and possible cohort effects. Inconsistency in cognitive test batteries across studies provides an additional source of variability in that tests may differ substantially in reliability, which impacts estimates of effect size (Baugh, 2002). Moreover, given that the various tests were not normed on the same sample, it is difficult to directly compare differences in effect sizes across tests/domains (Russell et al., 2005).

The Measurement and Treatment Research to Improve Cognition in Schizophrenia (MATRICS) Consensus Cognitive Battery (MCCB; (Nuechterlein and Green, 2006) is a compilation of independently owned and published tests that initially had normative data from non-overlapping samples. The MCCB has the advantage of being co-normed (i.e., normative data for each test collected from the same sample) on the non-psychiatric (NP) community sample from the MATRICS Psychometric and Standardization Study (MATRICS PASS; (Kern et al., 2008). The MCCB includes seven cognitive domains: speed of processing, attention/vigilance, working memory, verbal learning, visual learning, reasoning and problem solving, and social cognition. A brief description of the 10 tests comprising the MCCB can be found in Table 1. Five MCCB domains are assessed with one test each, thus the T-score and percentile for those domains are based on those individual tests. The speed of processing and working memory domains are assessed with multiple tests, and these domain scores are based on a composite of the included tests. In addition to the seven domain scores, the MCCB also provides an Overall Composite score, an index of cognitive functioning across domains. The Overall Composite score is derived through equal weighting of the seven MCCB domain scores (Nuechterlein and Green, 2006).

The profile of MCCB impairment for a CSz sample was previously reported (Kern et al., 2011). Compared to the NP sample, CSz patients were impaired across all MCCB domains, with greater relative impairment in speed of processing and working memory, and less relative impairment in reasoning and problem solving compared to their average performance across the remaining MCCB domains.

Adoption of the MCCB as a neuropsychological test battery in schizophrenia research is on the rise. At the time of this writing, ClinicalTrials.gov, an online registry of clinical trials across the globe maintained by the National Institutes of Health and National Library of Medicine, lists over 50 studies that employ the MCCB. The aim of this paper was to examine the overall magnitude and profile of cognitive impairment in FESz using the MCCB. Specifically, we compared MCCB domain scores for a FESz sample to data from CSz and NP participants in MATRICS PASS (Kern et al., 2011; Nuechterlein et al., 2008). Four hypotheses were tested: 1) that FESz patients would show significant impairment averaged across MCCB domains compared to NP; 2) that FESz patients would show similar 
magnitude of impairment as CSz patients; 3) consistent with the Mesholam-Gately metaanalysis (Mesholam-Gately et al., 2009), that FESz patients would exhibit particular weakness in speed of processing and verbal learning relative to performance in the remaining MCCB domains; and 4) finally, that the proportion of participants from each patient group who exhibit clinically-significant global cognitive impairment will not differ.

\section{Methods}

\subsection{Participants}

Three samples of participants provided data for these analyses. The FESz sample included 105 patients from the UCLA Aftercare Research Program, an outpatient research clinic for FESz. Inclusion criteria were: 1) onset of a first psychotic episode within 24 months of program entry, 2) fulfillment of DSM-IV (American Psychiatric Association, 1994) criteria for schizophrenia, schizoaffective disorder, depressed type, or schizophreniform disorder, 3) age of 18 to 45 years, and 4) sufficient fluency in English to allow for valid completion of the testing protocol. DSM-IV diagnoses were made using the Structured Clinical Interview for DSM-IV (SCID; First et al., 2001). These participants met criteria for schizophrenia ( $n=56)$, schizoaffective disorder, depressed type $(n=13)$, or schizophreniform disorder $(n=36)$.

The other two samples were from the five academic sites (Duke University, Harvard University, University of Kansas, Maryland Psychiatric Research Center, and UCLA) in MATRICS PASS (Kern et al., 2011; Nuechterlein et al., 2008). The CSz sample included 176 patients with a DSM-IV diagnosis of schizophrenia $(n=151)$ or schizoaffective disorder, depressed type ( $n=25)$. Inclusion criteria were: 1$)$ a DSM-IV diagnosis of schizophrenia or schizoaffective disorder, depressed type, based on SCID interview, 2) age 18-65 years, and 3) clinical stability as indicated by stable outpatient or rehabilitation center status and no medication changes in month prior to testing. The NP sample included 300 community residents aged 20-59, representative of the 2000 U.S. Census with respect to gender, race, ethnicity, and level of education.

Patients with a diagnosis of schizoaffective disorder, depressed type were included in these analyses because previous research suggests that the cognitive impairments associated with that diagnosis are comparable with those observed in schizophrenia (Bora et al., 2009; Simonsen et al., 2011). Exclusion criteria for all participants were: 1) history of neurological disorder or head injury, 2) IQ less than 70 or evidence of pervasive developmental disorder, 3 ) alcohol or substance abuse ( 1 month prior to testing) or dependence (6 months prior to testing) and/or excessive lifetime use of alcohol or substances, and 4) use of any medications that could interfere with test performance. In addition, for NP participants, history of schizophrenia or any other psychotic-spectrum disorder was exclusionary. Exclusion criteria were minimal in an effort to avoid creating a "super normal" comparison sample (Kendler, 1990). Informed consent was obtained from all participants using forms approved by the local IRBs.

Demographic information for all participants and clinical information for patient participants can be found in Table 2. FESz were substantially younger than CSz. As is typical, the two 
patient groups included more males than females in contrast to the stratified NP sample. All analyses of MCCB scores use age and gender correction based on the MCCB computer scoring program. The groups also differed in terms of race and ethnicity: compared to the NP sample, both patient groups had a lower proportion of Caucasians and a higher proportion of African Americans. In addition, the FESz sample had a higher proportion of Asian/Pacific Islanders and individuals of Hispanic ethnicity. Using the method of Andreasen and colleagues (Andreasen et al., 2010), chlorpromazine (CPZ) equivalents were calculated for antipsychotic medication dosing in the patient groups. The CSz group was prescribed a significantly higher mean equivalent dose of antipsychotic medication than the FESz group. In addition, the CSz group exhibited higher levels of positive and general symptoms, as assessed with the Brief Psychiatric Rating Scale (BPRS; (Ventura et al., 1993); the two patient groups did not differ on level of negative symptoms.

\subsection{Procedure}

FESz patients completed the MCCB (Nuechterlein and Green, 2006) as part of their baseline assessment. FESz patients were prescribed risperidone, and baseline testing typically occurred within three months of outpatient program entry after medication stabilization. Testing procedures are described for the CSz sample (Nuechterlein et al., 2008) and for the NP sample (Kern et al., 2008) in detail elsewhere. Briefly, CSz participants were administered the beta version of the MCCB which included the 10 tests along with an additional 10 candidate tests. NP participants were administered the final version of the MCCB. For patients prescribed antiparkinsonian medication, it was discontinued (if judged clinically feasible) 48 hours prior to testing to avoid anticholinergic effects on cognitive measures. Raw scores for each MCCB test were converted to age and gender corrected Tscores using the MCCB scoring program (mean $=50$, s.d. $=10$ ). For all participants, testing was conducted by bachelor's level examiners who received extensive training in administration of the MCCB. All examiners participated in a quality assurance program which included periodic checks on MCCB administration and scoring practices.

\subsection{Data Analysis}

A three (group) by seven (MCCB domain) mixed model analysis was conducted using IBM SPSS 21.0 Mixed Models. Follow-up analyses and contrasts were employed to decompose significant main effects and interactions. Within the mixed models analysis, follow-up single degree of freedom contrasts were conducted to examine the pattern of relative strengths and weaknesses in the MCCB profiles of the two patient groups. For each group, these contrasts compared performance on each MCCB domain with the average score on the remaining domains. MCCB Overall Composite scores were grouped by degree of impairment based on criteria outlined by Heaton et al. (Heaton et al., 1991) for use in clinical neuropsychology: "unimpaired" ( $\mathrm{T} \geq 45)$, "below average" $(\mathrm{T}=40-44)$, "mild impairment" ( $\mathrm{T}=35-39)$, "moderate impairment" (T=20-34), and "severe impairment" $(\mathrm{T}<20)$. Differences in distribution of severity of cognitive impairment across groups were assessed using chisquare analysis. 


\section{Results}

\subsection{Descriptive Statistics}

Age and gender corrected T-scores for each MCCB subtest and domain by group are presented in Table 3. Missing data were minimal (3.5\% of data points). The mixed models analyses use all available data. Calculation of the MCCB Overall Composite score was completed for subjects with complete data; the sample sizes for the MCCB Overall Composite score chi-square analysis were $99 \mathrm{FESz}, 167 \mathrm{CSz}$, and 289 NP.

\subsection{Mixed Models Analysis}

The MCCB profiles for each group are presented in Figure 1. A mixed model was fit to the data, with diagnostic group $(n=3)$, MCCB domain $(n=7)$ entered as fixed effects. The initial run of the analysis included the following variables as potential covariates: ethnicity, race, antipsychotic medication dosing (CPZ equivalents), BPRS positive symptoms, and BPRS general symptoms. Only ethnicity and race showed statistically significant fixed effects, thus, these two variables were retained as covariates in the final model. There was a significant main effect of group $[F(2,573.12)=160.31, p<0.001]$, a significant main effect of MCCB domain $[F(6,3437.37)=12.26, p<0.001]$, and a significant group by MCCB domain interaction $[F(12,3437.25)=7.71, p<0.001]$. Pairwise comparisons to decompose the main effect of group demonstrated that the average score across MCCB domains for the NP group was significantly higher than for FESz $[t(1726.69)=-5.19, p<0.01$; mean difference $=-6.89$, 95\%CI: $-9.49,-4.29]$ and CSz [ $t(2061.82)=-13.08, p<0.01$, mean difference $=-13.65$, 95\%CI: $-15.70,-11.60]$. Thus, hypothesis 1 was supported; the FESz sample evidenced significant impairment across MCCB domains compared to NP. The significant interaction effect indicated that the MCCB profile of the two patient groups significantly differed from that of the control group.

To evaluate hypotheses 2 and 3, i.e., the degree of similarity of cognitive impairment averaged across MCCB domains and MCCB performance profiles of the patient groups, a mixed model analysis was conducted comparing only the two patient groups. There was no main effect of group $[F(1,275.55)=1.50, p=0.23]$, indicating similar magnitude of impairment averaged across MCCB domains in the two patient groups. There was a significant main effect of MCCB domains $[F(6,1657.99)=13.73, p<0.01]$ and a significant group by MCCB domain interaction $[F(6,1657.97)=6.84, p<0.01]$. Follow-up contrasts demonstrated a significant difference between the FESz and CSz groups on working memory $[F(1,274)=13.14, p<0.01]$ and social cognition $[F(1,268)=5.16, p=0.02]$, with the FESz group achieving higher scores in both domains.

Next, within each patient group, we examined the pattern of relative strengths and weaknesses in the MCCB profiles. Within each group, performance on each MCCB domain was compared to the average score of the remaining domains. Hypothesis 3 was partially supported; FESz patients exhibited relative weakness in speed of processing $[t(616.01)=$ $-6.46, p<0.001$, mean difference $=-5.9795 \% \mathrm{CI}:-7.79,-4.16]$, and relative strength in working memory $[t(616.01)=4.68, p<0.001$, mean difference $=4.33,95 \%$ CI: $2.51,6.14]$ and social cognition $[t(617.00)=2.14, p=0.03$, mean difference $=2.01,95 \%$ CI: $0.16,3.86]$. 
Contrary to our hypothesis, FESz patients did not exhibit relative weakness in verbal learning and there was trend in the opposite direction $[t(616.01)=1.69, p=0.09$, mean difference $=1.56,95 \% \mathrm{CI}:-0.25,3.38]$.

CSz patients exhibited relative weakness in speed of processing $[t(1042.13)=-5.67$, $p<0.001$, mean difference $=-4.19,95 \% \mathrm{CI}:-5.64,-2.74]$ and working memory $[t(1041.47)=$ $-2.40, p=0.02$, mean difference $=-1.77,95 \% \mathrm{CI}:-3.21,-0.32]$, and relative strength in reasoning and problem solving $[t(1041.12)=3.69, p<0.001$, mean difference $=2.70,95 \%$ CI: $1.26,4.14]$ and visual learning $[t(1041.12)=2.10, p=0.04$, mean difference $=1.54,95 \%$ CI: $0.10,2.98]$. Thus, these data suggest presence of subtle differences in the MCCB profiles for FESz and CSz: although both patient groups show significant impairment across MCCB domains compared to NP, FESz show mild relative sparing of working memory and social cognition compared to CSz.

\subsection{Distribution of Clinically-significant Global Cognitive Impairment across Groups}

Finally, using chi-square analysis, we tested whether distribution of impairment in the MCCB Overall Composite score differed among the three groups (see Table 4). The distribution pattern for the two patient groups was similar, while the distribution pattern of the NP group was significantly different from both patient groups $\left[\chi^{2}(8)=240.46, p<0.01\right]$. Specifically, the patient groups were overrepresented in the moderate and severe impairment categories, and underrepresented in the unimpaired category.

\section{Discussion}

Utilizing the MCCB, a cognitive battery co-normed on a non-psychiatric (NP) community sample, we provide a profile analysis of cognitive impairment in first-episode schizophrenia. Our analyses demonstrate that the overall magnitude and pattern of cognitive impairment in FESz is similar to that observed in CSz. Both FESz and CSz evidence marked impairment across MCCB domains compared to NP. Despite the similarity of MCCB performance profiles in FESz and CSz, subtle differences were observed. Although both patient groups exhibited relative weakness in speed of processing in within group comparisons, FESz patients exhibited relative strength in working memory, while CSz patients exhibited relative weakness in this domain. Also, the working memory and social cognition scores for the FESz group were significantly higher than that of the CSz group.

These results suggest that, in addition to diffuse impairment across cognitive domains, individuals with schizophrenia show particular weakness in speed of information processing, even early in the illness. For both patient groups, speed of processing was approximately 5 T-score points (i.e., 0.5 s.d.) below the mean performance of each group across the remaining MCCB domains. Some investigators have suggested that speed of processing underlies many of the cognitive deficits observed in schizophrenia, and serves as a ratelimiting factor for cognitive performance (e.g., (Dickinson et al., 2007; Ojeda et al., 2012). Weakness in speed of processing on the MCCB relative to the other domains has been reported elsewhere in the literature (August et al., 2012). One possible explanation is that this finding is simply an artifact of the psychometric properties of the MCCB; the speed of processing domain is comprised of three tests and, hence, may be more reliably measured 
than other MCCB domains. However, while the test-retest reliability for speed of processing may be higher than that of verbal learning and visual learning, the differences between speed of processing and the remaining MCCB domains were negligible (Keefe et al., 2011). Thus, differences in reliability across domains are unlikely to account for this pattern. Another possible explanation is increased measurement sensitivity from including multiple, imperfectly correlated measures of a domain that together sample that domain more broadly (see (Kern et al., 2011). Hence, standardized scores from domains measured by more than one test will tend to be lower than domains measured by a single test. Contrary to predictions, this FESz sample did not exhibit weakness in verbal learning relative to other domains. Perhaps the use of a word list learning task contributes to the lack of particular weakness in verbal learning on the MCCB. In the meta-analysis (Mesholam-Gately et al., 2009), the effect size for the immediate verbal learning and memory was largest for studies that employed a test of prose (the Wechsler Memory Scale Logical Memory test, SMD= -1.5 ) versus word list learning tasks (HVLT-R, $\mathrm{SMD}=-1.15$ ).

This first-episode sample exhibited less impairment in working memory and social cognition compared to the chronic schizophrenia sample, raising the possibility that these cognitive abilities decline over the course of illness. Studies of cognition in schizophrenia have yielded inconsistent findings regarding stability versus progressive decline. Regarding working memory, some cross-sectional studies comparing FESz to CSz have reported greater impairment in CSz (Bilder et al., 1992; Braw et al., 2008; Lee and Park, 2005). However, longitudinal studies generally report stability, or even slight improvement, in working memory over time (Albus et al., 2006; Gonzalez-Ortega et al., 2013; RodriguezSanchez et al., 2013; Rund et al., 2007). Gonzalez-Ortega and colleagues (Gonzalez-Ortega et al., 2013) also found working memory to be relatively less impaired than other cognitive domains at initial assessment and note stability over five year follow-up in FESz patients, even though there was significant improvement in other cognitive domains. Working memory performance may be negatively impacted by illness chronicity and number of relapses (Barder et al., 2013a).

Cross-sectional studies of social cognition suggest similar levels of impairment in FESz and CSz (Addington and Addington, 2008; Addington et al., 2006; Comparelli et al., 2013; Comparelli et al., 2011; Pinkham et al., 2007). Regarding the MSCEIT specifically, a recent cross-sectional study demonstrated no significant difference between a FESz sample and a schizophrenia sample with a 10-12 year duration of illness on the Managing Emotions Branch (Green et al., 2012). In contrast, sparing of performance on the MSCEIT Managing Emotions Branch has been reported in a younger recent-onset sample (Holmen et al., 2010). Because both the Green et al. results and the current analyses are cross-sectional in nature, they cannot rule out cohort effects. Longitudinal studies of the MCCB performance profile in FESz can more directly examine evidence for decline in working memory and social cognition over the course of illness. Longitudinal follow-up of this first-episode sample is currently underway.

Despite small differences in the MCCB profile between patient groups, the distribution of impairment on the MCCB Overall Composite score did not significantly differ between FESz and CSz. Both patient groups were over-represented in the moderately and severely 
impaired range, and clearly under-represented in the unimpaired range. In our sample, 59\% of FESz patients exhibited moderate to severe levels cognitive impairment (i.e., equivalent to a score of at least 1.5 standard deviations below mean NP performance) on the MCCB Overall Composite score. These results are very consistent with those reported by Rund and colleagues (Rund et al., 2006). Moreover, only 17\% of FESz patients in the current sample were classified as within the unimpaired range. Thus, most schizophrenia patients present with clinically significant global impairment in cognition at illness onset.

As noted above, one limitation of this study is the cross-sectional design, which does not control for potential cohort effects. In addition, group differences on a number of clinical and demographic variables were notable for the two patient samples. However, it is important to note that the potential impact of these variables was considered in the mixed models analyses. Finally, the patient groups were not matched for age, which is difficult to avoid given that the patient groups were at different developmental stages of the illness. However, the scores for each MCCB domain and the Overall Composite were age and gender corrected based on the MCCB community normative sample. Longitudinal studies of cognition across phase of illness are needed to ensure that the group tendencies observed in the current study hold within subjects over time.

In sum, our analyses suggest that overall, patients early in the course of schizophrenia exhibit similar magnitude of impairment on the MCCB compared to patients with a chronic course of illness. Both patient groups exhibited marked impairment in speed of processing; however, subtle differences in the MCCB profile were observed between patient groups because of relative sparing of working memory and social cognition in FESz. Beyond this cross-sectional study, longitudinal studies of MCCB performance during the transition from early to chronic phases of schizophrenia are needed to determine whether progressive decline occurs in some cognitive domains.

\section{Acknowledgments}

We thank the patients and community comparison subjects for their participation in this study. We gratefully acknowledge the assistance of the UCLA Aftercare Research Program research assistants Jacqueline Hayata, B.A., Robin Kite, M.A., and Lilian Medina, B.A., and clinic staff Laurie Casaus, M.D., John Luo, M.D., Kimberly Baldwin, M.F.T., Rosemary Collier, M.A., Nicole R. DeTore, M.A., Yurika Sturdevant, Psy.D., and Luana Turner, Psy.D. We also thank MATRICS PASS site PIs Lyle E. Baade, Ph.D., James M. Gold, Ph.D., Richard S.E. Keefe, Ph.D., and Larry J. Seidman, Ph.D., for their key roles in that earlier project.

\section{References}

Addington J, Addington D. Cognitive functioning in first-episode schizophrenia. Journal of Psychiatry and Neuroscience. 2002; 27(3):188-192. [PubMed: 12066448]

Addington J, Addington D. Social and cognitive functioning in psychosis. Schizophrenia research. 2008; 99(1-3):176-181. [PubMed: 17681756]

Addington J, Saeedi H, Addington D. Facial affect recognition: a mediator between cognitive and social functioning in schizophrenia? Schizophrenia Research. 2006; 85:142-150. [PubMed: 16678388]

Albus M, Hubmann W, Mohr F, Hecht S, Hinterberger-Weber P, Seitz NN, Kuchenhoff H. Neurocognitive functioning in patients with first-episode schizophrenia : results of a prospective 5year follow-up study. Eur Arch Psychiatry Clin Neurosci. 2006; 256(7):442-451. [PubMed: 17031490] 
Albus M, Hubmann W, Wahlheim C, Sobizack N, Franz U, Mohr F. Contrasts in neuropsychological test profile between outpatients with first-episode schizophrenia. Acta Psychiutr Scand. 1996; 94:87-93.

American Psychiatric Association. Diagnostic and Statistical Manual of Mental Disorders (DSM-IV). 4. American Psychiatric Press; Washington, DC: 1994.

Andreasen NC, Pressler M, Nopoulos P, Miller D, Ho BC. Antipsychotic dose equivalents and doseyears: a standardized method for comparing exposure to different drugs. Biol Psychiatry. 2010; 67(3):255-262. [PubMed: 19897178]

August SM, Kiwanuka JN, McMahon RP, Gold JM. The MATRICS Consensus Cognitive Battery (MCCB): clinical and cognitive correlates. Schizophr Res. 2012; 134(1):76-82. [PubMed: 22093182]

Barder HE, Sundet K, Rund BR, Evensen J, Haahr U, Ten Velden Hegelstad W, Joa I, Johannessen JO, Langeveld H, Larsen TK, Melle I, Opjordsmoen S, Rossberg JI, Simonsen E, Vaglum P, McGlashan T, Friis S. Neurocognitive development in first episode psychosis 5 years follow-up: associations between illness severity and cognitive course. Schizophr Res. 2013a; 149(1-3):63-69. [PubMed: 23810121]

Barder HE, Sundet K, Rund BR, Evensen J, Haahr U, Ten Velden Hegelstad W, Joa I, Johannessen JO, Langeveld J, Larsen TK, Melle I, Opjordsmoen S, Rossberg JI, Simonsen E, Vaglum P, McGlashan T, Friis S. Ten year neurocognitive trajectories in first-episode psychosis. Front Hum Neurosci. 2013b; 7:643. [PubMed: 24109449]

Baugh F. Correcting Effect Sizes for Score Reliability: A Reminder that Measurement and Substantive Issues are Linked Inextricably. Educational and Psychological Measurement. 2002; 62(2):254263.

Bilder RM, Lipschutz-Broch L, Reiter G, Geisler SH, Mayerhoff DI, Lieberman JA. Intellectual deficits in first-episode schizophrenia: Evidence for progressive deterioration. Schizophrenia Bulletin. 1992; 18:437-448. [PubMed: 1411331]

Bora E, Yucel M, Pantelis C. Cognitive functioning in schizophrenia, schizoaffective disorder and affective psychoses: meta-analytic study. The British Journal of Psychiatry. 2009; 195(6):475482. [PubMed: 19949193]

Braw Y, Bloch Y, Mendelovich S, Ratzoni G, Gal G, Harari H, Tripto A, Levkovitz Y. Cognition in young schizophrenia outpatients: comparison of first-episode with multiepisode patients. Schizophr Bull. 2008; 34(3):544-554. [PubMed: 17984299]

Comparelli A, Corigliano V, De Carolis A, Mancinelli I, Trovini G, Ottavi G, Dehning J, Tatarelli R, Brugnoli R, Girardi P. Emotion recognition impairment is present early and is stable throughout the course of schizophrenia. Schizophr Res. 2013; 143(1):65-69. [PubMed: 23218561]

Comparelli A, De Carolis A, Corigliano V, Romano S, Kotzalidis GD, Campana C, Ferracuti S, Tatarelli R, Girardi P. Subjective disturbance of perception is related to facial affect recognition in schizophrenia. J Nerv Ment Dis. 2011; 199(10):802-806. [PubMed: 21964276]

Cornblatt B, Obuchowski M, Roberts S, Pollack S, Erlenmeyer-Kimling L. Cognitive and behavioral precursors of schizophrenia. Development and Psychopathology. 1999; 11:487-508. [PubMed: 10532621]

Dickinson D, Ragland JD, Gold JM, Gur RC. General and specific cognitive deficits in schizophrenia: Goliath defeats David? Biol Psychiatry. 2008; 64(9):823-827. [PubMed: 18472089]

Dickinson D, Ramsey ME, Gold JM. Overlooking the obvious: a meta-analytic comparison of digit symbol coding tasks and other cognitive measures in schizophrenia. Arch Gen Psychiatry. 2007; 64(5):532-542. [PubMed: 17485605]

First, M.; Spitzer, R.; Gibbon, M.; Williams, J. Structured Clinical Interview for DSM-IV Axis I Disorders - Patient Edition (SCID-I/P). Biometrics Research Department, New York State Psychiatric Institute; New York: 2001.

Gold JM. Cognitive deficits as treatment targets in schizophrenia. Schizophrenia Research. 2004; 72(1):21-28. [PubMed: 15531404]

Gold S, Arndt S, Nopoulos P, O'Leary DS, Andreasen NC. Longitudinal study of cognitive function in first-episode and recent-onset schizophrenia. Am J Psychiatry. 1999; 156(9):1342-1348. [PubMed: 10484943] 
Gonzalez-Blanch C, Rodriguez-Sanchez JM, Perez-Iglesias R, Pardo-Garcia G, Martinez-Garcia O, Vazquez-Barquero JL, Crespo-Facorro B. First-episode schizophrenia patients neuropsychologically within the normal limits: evidence of deterioration in speed of processing. Schizophr Res. 2010; 119(1-3):18-26. [PubMed: 20335007]

Gonzalez-Ortega I, de Los Mozos V, Echeburua E, Mezo M, Besga A, Ruiz de Azua S, GonzalezPinto A, Gutierrez M, Zorrilla I. Working memory as a predictor of negative symptoms and functional outcome in first episode psychosis. Psychiatry Res. 2013; 206(1):8-16. [PubMed: 22985548]

Green MF. Cognitive impairment and functional outcome in schizophrenia and bipolar disorder. J Clin Psychiatry. 2006; 67(10):e12. [PubMed: 17107235]

Green MF, Bearden CE, Cannon TD, Fiske AP, Hellemann GS, Horan WP, Kee K, Kern RS, Lee J, Sergi MJ, Subotnik KL, Sugar CA, Ventura J, Yee CM, Nuechterlein KH. Social cognition in schizophrenia, Part 1: performance across phase of illness. Schizophr Bull. 2012; 38(4):854-864. [PubMed: 21345917]

Green MF, Nuechterlein KH. Should schizophrenia be treated as a neurocognitive disorder? Schizophrenia Bulletin. 1999; 25:309-319. [PubMed: 10416733]

Hawkins KA, Addington J, Keefe RS, Christensen B, Perkins DO, Zipurksy R, Woods SW, Miller TJ, Marquez E, Breier A, McGlashan TH. Neuropsychological status of subjects at high risk for a first episode of psychosis. Schizophr Res. 2004; 67(2-3):115-122. [PubMed: 14984870]

Heaton, RK.; Grant, I.; Matthews, CG. Comprehensive Norms for an Expanded Halstead-Reitan Battery: Demographic Corrections, Research Findings, and Clinical Applications. Psychological Assessment Resources, Inc; Odessa, FL: 1991.

Heinrichs RW, Zakzanis KK. Neurocognitive deficits in schizophrenia: A quantitative review of the evidence. Neuropsychology. 1998; 12(3):426-445. [PubMed: 9673998]

Hoff AL, Riordan H, O'Donnell DW, Morris L, DeLisi LE. Neuropsychological functioning of firstepisode schizophreniform patients. American Journal of Psychiatry. 1992; 149:898-903. [PubMed: 1609868]

Hoff AL, Sakuma M, Wieneke M, Horon R, Kushner M, DeLisi LE. Longitudinal neuropsychological follow-up study of patients with first-episode schizophrenia. American Journal of Psychiatry. 1999; 156(9):1336-1341. [PubMed: 10484942]

Hoff AL, Svetina C, Shields G, Stewart J, DeLisi LE. Ten year longitudinal study of neuropsychological functioning subsequent to a first episode of schizophrenia. Schizophr Res. 2005; 78(1):27-34. [PubMed: 15964177]

Holmen A, Juuhl-Langseth M, Thormodsen R, Melle I, Rund BR. Neuropsychological profile in earlyonset schizophrenia-spectrum disorders: measured with the MATRICS battery. Schizophr Bull. 2010; 36(4):852-859. [PubMed: 19223656]

Keefe RS, Bilder RM, Davis SM, Harvey PD, Palmer BW, Gold JM, Meltzer HY, Green MF, Capuano G, Stroup TS, McEvoy JP, Swartz MS, Rosenheck RA, Perkins DO, Davis CE, Hsiao JK, Lieberman JA. Neurocognitive effects of antipsychotic medications in patients with chronic schizophrenia in the CATIE Trial. Arch Gen Psychiatry. 2007; 64(6):633-647. [PubMed: 17548746]

Keefe RSE, Fox KH, Harvey PD, Cucchiaro J, Siu C, Loebel A. Characteristics of the MATRICS Consensus Cognitive Battery in a 29-site antipsychotic schizophrenia clinical trial. Schizophrenia Research. 2011; 125(2-3):161-168. [PubMed: 21075600]

Kendler KS. The super-normal control group in psychiatric genetics: Possible artifactual evidence for co-aggregation. Psychiatric Genetics. 1990; 1:45-53.

Kern RS, Gold JM, Dickinson D, Green MF, Nuechterlein KH, Baade LE, Keefe RS, MesholamGately RI, Seidman LJ, Lee C, Sugar CA, Marder SR. The MCCB impairment profile for schizophrenia outpatients: results from the MATRICS psychometric and standardization study. Schizophr Res. 2011; 126(1-3):124-131. [PubMed: 21159492]

Kern RS, Nuechterlein KH, Green MF, Baade LE, Fenton WS, Gold JM, Keefe RS, Mesholam-Gately R, Mintz J, Seidman LJ, Stover E, Marder SR. The MATRICS Consensus Cognitive Battery, part 2: Co-norming and standardization. American Journal of Psychiatry. 2008; 165(2):214-220. [PubMed: 18172018] 
Lee J, Park S. Working memory impairments in schizophrenia: a meta-analysis. Journal of Abnormal Psychology. 2005; 114(4):599-611. [PubMed: 16351383]

Lencz T, Smith CW, McLaughlin D, Auther A, Nakayama E, Hovey L, Cornblatt BA. Generalized and specific neurocognitive deficits in prodromal schizophrenia. Biol Psychiatry. 2006; 59(9):863871. [PubMed: 16325151]

Lewandowski KE, Cohen BM, Ongur D. Evolution of neuropsychological dysfunction during the course of schizophrenia and bipolar disorder. Psychol Med. 2011; 41(2):225-241. [PubMed: 20836900]

Mesholam-Gately RI, Giuliano AJ, Goff KP, Faraone SV, Seidman LJ. Neurocognition in first-episode schizophrenia: a meta-analytic review. Neuropsychology. 2009; 23(3):315-336. [PubMed: 19413446]

Mohamed S, Paulsen JS, O'Leary D, Arndt S, Andreasen N. Generalized cognitive deficits in schizophrenia: a study of first-episode patients. Archives of General Psychiatry. 1999; 56(8):749_ 754. [PubMed: 10435610]

Nuechterlein KH, Dawson ME, Gitlin M, Ventura J, Goldstein MJ, Snyder KS, Yee CM, Mintz J. Developmental processes in schizophrenic disorders: Longitudinal studies of vulnerability and stress. Schizophrenia Bulletin. 1992; 18(3):387-425. [PubMed: 1411329]

Nuechterlein, KH.; Green, MF. MATRICS Consensus Cognitive Battery. MATRICS Assessment, Inc; Los Angeles: 2006.

Nuechterlein KH, Green MF, Kern RS, Baade LE, Barch DM, Cohen JD, Essock S, Fenton WS, Frese FJ 3rd, Gold JM, Goldberg T, Heaton RK, Keefe RS, Kraemer H, Mesholam-Gately R, Seidman LJ, Stover E, Weinberger DR, Young AS, Zalcman S, Marder SR. The MATRICS Consensus Cognitive Battery, part 1: Test selection, reliability, and validity. American Journal of Psychiatry. 2008; 165(2):203-213. [PubMed: 18172019]

Ojeda N, Pena J, Schretlen DJ, Sanchez P, Aretouli E, Elizagarate E, Ezcurra J, Gutierrez M. Hierarchical structure of the cognitive processes in schizophrenia: the fundamental role of processing speed. Schizophrenia Research. 2012; 135(1-3):72-78. [PubMed: 22226902]

Pinkham AE, Penn DL, Perkins DO, Graham KA, Siegel M. Emotion perception and social skill over the course of psychosis: a comparison of individuals "at-risk" for psychosis and individuals with early and chronic schizophrenia spectrum illness. Cogn Neuropsychiatry. 2007; 12(3):198-212. [PubMed: 17453901]

Rodriguez-Sanchez JM, Ayesa-Arriola R, Perez-Iglesias R, Perianez JA, Martinez-Garcia O, GomezRuiz E, Tabares-Seisdedos R, Crespo-Facorro B. Course of cognitive deficits in first episode of non-affective psychosis: a 3-year follow-up study. Schizophr Res. 2013; 150(1):121-128. [PubMed: 23899999]

Rund BR. A review of longitudinal studies of cognitive functions in schizophrenia patients. Schizophrenia Bulletin. 1998; 24(3):425-435. [PubMed: 9718634]

Rund BR, Melle I, Friis S, Johannessen JO, Larsen TK, Midbøe LJ, Opjordsmoen S, Simonsen E, Vaglum P, McGlashan T. The course of neurocognitive functioning in first-episode psychosis and its relation to premorbid adjustment, duration of untreated psychosis, and relapse. Schizophrenia research. 2007; 91(1-3):132-140. [PubMed: 17258891]

Rund BR, Sundet K, Asbjørnsen A, Egeland J, Landrø NI, Lund A, Roness A, Stordal KI, Hugdahl K. Neuropsychological test profiles in schizophrenia and non-psychotic depression. Acta Psychiatrica Scandinavica. 2006; 113(4):350-359. [PubMed: 16638080]

Russell EW, Russell SL, Hill BD. The fundamental psychometric status of neuropsychological batteries. Arch Clin Neuropsychol. 2005; 20(6):785-794. [PubMed: 15935610]

Saykin AJ, Shtasel DL, Gur RE, Kester DB. Neuropsychological deficits in neuroleptic naive patients with first-episode schizophrenia. Archives of General Psychiatry. 1994; 51(2):124-131. [PubMed: 7905258]

Seidman LJ, Giuliano AJ, Meyer EC, Addington J, Cadenhead KS, Cannon TD, McGlashan TH, Perkins DO, Tsuang MT, Walker EF, Woods SW, Bearden CE, Christensen BK, Hawkins K, Heaton R, Keefe RS, Heinssen R, Cornblatt BA. Neuropsychology of the prodrome to psychosis in the NAPLS consortium: relationship to family history and conversion to psychosis. Arch Gen Psychiatry. 2010; 67(6):578-588. [PubMed: 20530007] 
Simon AE, Cattapan-Ludewig K, Zmilacher S, Arbach D, Gruber K, Dvorsky DN, Roth B, Isler E, Zimmer A, Umbricht D. Cognitive functioning in the schizophrenia prodrome. Schizophr Bull. 2007; 33(3):761-771. [PubMed: 17412711]

Simonsen C, Sundet K, Vaskinn A, Birkenaes AB, Engh JA, Færden A, Jónsdóttir H, Ringen PA, Opjordsmoen S, Melle I, Friis S, Andreassen OA. Neurocognitive Dysfunction in Bipolar and Schizophrenia Spectrum Disorders Depends on History of Psychosis Rather Than Diagnostic Group. Schizophrenia Bulletin. 2011; 37(1):73-83. [PubMed: 19443616]

Townsend LA, Norman RM. Course of cognitive functioning in first episode schizophrenia spectrum disorders. Expert Rev Neurother. 2004; 4(1):61-68. [PubMed: 15853616]

Ventura J, Lukoff D, Nuechterlein KH, Liberman RP, Green MF, Shaner A. Brief Psychiatric Rating Scale (BPRS) expanded version: Scales, anchor points, and administration manual. International Journal of Methods in Psychiatric Research. 1993; 3:227-243. 


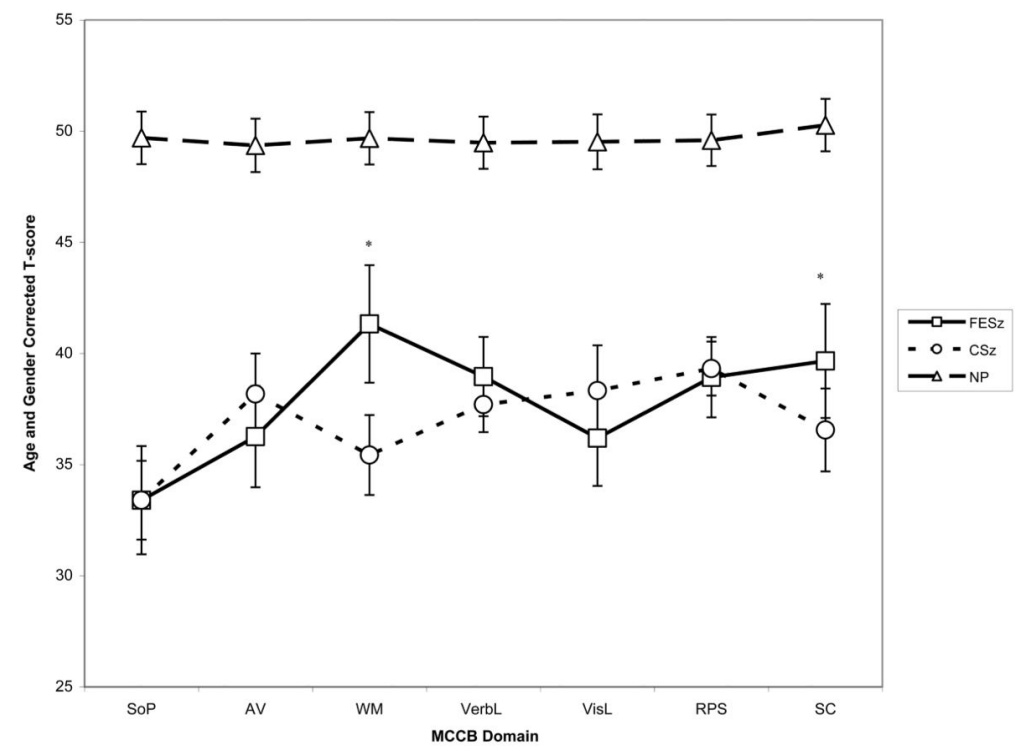

Figure 1.

MCCB profile for FESz, CSz, and NP (mean age and gender corrected T-score, 95\% confidence interval)

Note: SoP: Speed of Processing, AV: Attention/Vigilance, WM: Working Memory, VerbL: Verbal Learning, VisL: Visual Learning, RPS: Reasoning and Problem Solving, SC: Social Cognition, FESz: first-episode schizophrenia, CSz: chronic schizophrenia, NP: nonpsychiatric community comparison sample.

*Denotes significant difference between FESz and CSz 


\section{Table 1}

Description of MATRICS Consensus Cognitive Battery tests

\begin{tabular}{|c|c|c|}
\hline Domain & Test & Variable of interest \\
\hline \multirow[t]{3}{*}{ Speed of Processing } & BACS Symbol Coding Test (BACS SC) & Total number correct \\
\hline & Category Fluency Test, Animal Naming (Fluency) & Total number of animals named in 60 seconds \\
\hline & Trail Making Test, Part A (TMTA) & Time to completion \\
\hline Attention/Vigilance & Continuous Performance Test, Identical Pairs (CPT-IP) & Overall d \\
\hline \multirow[t]{2}{*}{ Working Memory } & WMS $3^{\text {rd }}$ ed., Spatial Span (WMS-III SS) & $\begin{array}{l}\text { Sum of raw scores on forward and backward } \\
\text { conditions }\end{array}$ \\
\hline & Letter-Number Span Test (LNS) & Number of correct trials \\
\hline Verbal Learning & Hopkins Verbal Learning Test - Revised (HVLT-R) & $\begin{array}{l}\text { Total number of words recalled correctly over three } \\
\text { learning trials }\end{array}$ \\
\hline Visual Learning & Brief Visual Memory Test - Revised (BVMT-R) & Total recall score over three learning trials \\
\hline $\begin{array}{l}\text { Reasoning \& Problem } \\
\text { Solving }\end{array}$ & NAB Mazes Subtest (NAB Mazes) & Total raw score \\
\hline Social Cognition & MSCEIT Managing Emotions Branch (MSCEIT- ME) & Branch score using general consensus scoring \\
\hline
\end{tabular}

Note: BACS: Brief Assessment of Cognition in Schizophrenia, WMS-III: Wechsler Memory Scale $-3^{\text {rd }}$ Ed., NAB: Neuropsychological Assessment Battery, MSCEIT: Mayer-Salovey-Caruso Emotional Intelligence Test. 
Table 2

Clinical and demographic information by group

\begin{tabular}{|c|c|c|c|}
\hline & $\begin{array}{l}\text { FESz }(n=105) \\
\text { Mean }(s . d .)\end{array}$ & $\begin{array}{l}\operatorname{CSz}(n=176) \\
\text { Mean (s.d.) }\end{array}$ & $\begin{array}{l}\text { NP }(n=300) \\
\text { Mean }(s . d .)\end{array}$ \\
\hline Age (years) & $22.1(3.7)^{a, b}$ & $44.0(11.2)$ & $42.6(11.6)$ \\
\hline Education (years) & $12.6(1.9)^{b}$ & $12.4(2.4)^{c}$ & $14.4(2.6)$ \\
\hline Illness chronicity (years) & $0.5(0.4)^{a}$ & $19.5(11.0)$ & \\
\hline BPRS total & $37.7(9.3)^{a}$ & $47.3(13.6)$ & \\
\hline Positive symptoms & $5.7(2.9)^{a}$ & $7.7(3.8)$ & \\
\hline Negative symptoms & $5.7(2.5)$ & $6.0(2.6)$ & \\
\hline General symptoms & $26.8(6.2)^{a}$ & $33.6(10.8)$ & \\
\hline \multirow[t]{2}{*}{ Antipsychotic medication dosing (CPZ equiv.) } & $302.7(127.7)^{a}$ & $552.3(374.5)$ & \\
\hline & $\underline{n}(\%)$ & $\underline{n}(\%)$ & $\underline{n}(\%)$ \\
\hline Gender & 79 male $(75.2 \%)$ & 134 male $(76.1 \%)$ & 141 male $(47.0 \%)$ \\
\hline \multicolumn{4}{|l|}{ Ethnicity } \\
\hline Hispanic/Latino & $43(41.0 \%)^{a, b}$ & $11(6.3 \%)$ & $17(5.7 \%)$ \\
\hline \multicolumn{4}{|l|}{ Race } \\
\hline Caucasian & $57(54.3 \%)^{b}$ & $115(65.3 \%)^{c}$ & $228(76.0 \%)$ \\
\hline African American & $30(28.6 \%)^{b}$ & $51(29.0 \%)^{c}$ & $53(17.7 \%)$ \\
\hline Asian/Pacific Islander & $12(11.4 \%)^{a, b}$ & $2(1.1 \%)$ & $7(2.3 \%)$ \\
\hline Other & $6(5.7 \%)$ & $8(4.5 \%)$ & $12(4.0 \%)$ \\
\hline Atypical antipsychotic medication & $105(100 \%)^{a}$ & $146(83.0 \%)$ & \\
\hline Antiparkinsonian medication & $31(29.5 \%)$ & $34(19.3 \%)$ & \\
\hline Benzodiazepine medication & $7(6.7 \%)^{a}$ & $31(17.6 \%)$ & \\
\hline Anticonvulsant medication & $1(1.0 \%)^{a}$ & $33(18.8 \%)$ & \\
\hline Antidepressant medication & $36(34.3 \%)$ & $73(41.5 \%)$ & \\
\hline Anxiolytic medication & $1(1.0 \%)$ & $3(1.7 \%)$ & \\
\hline
\end{tabular}

Note: FESz: first-episode schizophrenia, CSz: chronic schizophrenia, NP: non-psychiatric community comparison sample, BPRS: Brief Psychiatric Rating Scale, CPZ equiv.: chlorpromazine equivalent,

${ }^{a}$ FESz differs from CSz, $p<0.05$,

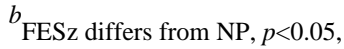

${ }^{c} \mathrm{CSz}$ differs from NP, $p<0.05$. 
Table 3

Mean MCCB subtest and domain age and gender corrected T-scores by group

\begin{tabular}{llll}
\hline MCCB Variable & $\begin{array}{l}\text { FESz } \\
\text { Mean }(\boldsymbol{s . d} .)\end{array}$ & $\begin{array}{l}\text { CSz } \\
\text { Mean }(\boldsymbol{s . d} .)\end{array}$ & $\begin{array}{l}\text { NP } \\
\text { Mean (s.d. })\end{array}$ \\
\hline Speed of Processing & $32.5(12.7)$ & $33.4(11.9)$ & $49.7(10.5)^{b}$ \\
$\quad 32.4(12.2)$ & $35.7(11.3)$ & $50.0(10.0)$ \\
$\quad$ BACS SC & $38.9(8.2)$ & $41.8(10.2)$ & $50.0(10.0)$ \\
$\quad 39.1(14.0)$ & $37.1(11.5)$ & $50.0(10.0)$ \\
TMTA & $36.3(11.7)$ & $38.2(12.2)$ & $49.4(10.5)^{b}$ \\
Attention/Vigilance (CPT-IP) & $41.3(13.8)^{a}$ & $35.4(12.1)$ & $49.7(10.4)^{b}$ \\
Working Memory & $45.0(12.8)$ & $41.4(10.3)$ & $50.0(10.0)$ \\
$\quad$ WMS-III SS & $40.6(12.7)$ & $37.6(12.0)$ & $50.0(10.0)$ \\
$\quad$ LNS & $39.0(9.3)$ & $37.7(8.4)$ & $49.5(10.4)^{b}$ \\
Verbal Learning (HVLT-R) & $36.2(11.2)$ & $38.3(13.8)$ & $49.5(10.9)^{b}$ \\
Visual Learning (BVMT-R) & $38.9(9.5)$ & $39.3(8.2)$ & $49.6(10.2)^{b}$ \\
Reasoning \& Problem Solving (NAB Mazes) & $39.6(13.1)^{a}$ & $36.6(12.5)$ & $50.3(10.4)^{b}$ \\
Social Cognition (MSCEIT-ME) & $30.6(13.5)$ & $28.6(12.7)$ & $49.6(11.1)^{b}$ \\
\hline MCCB Overall Composite & & &
\end{tabular}

Note: BACS SC: Brief Assessment of Cognition in Schizophrenia Symbol Coding, TMTA: Trailmaking Test A, CPT-IP: Continuous Performance Test - Identical Pairs, WMS-III SS: Wechsler Memory Scale $-3^{\text {rd }}$ Ed. Spatial Span, LNS: Letter-Number Span, HVLT-R: Hopkins Verbal Learning Test - Revised, BVMT-R: Brief Visuospatial Memory Test - Revised, NAB: Neuropsychological Assessment Battery, MSCEIT-ME: Mayer-Salovey-Caruso Emotional Intelligence Test - Managing Emotions, FESz: first-episode schizophrenia, CSz: chronic schizophrenia, NP: non-psychiatric community comparison sample,

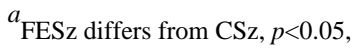

${ }^{b} \mathrm{NP}$ differs from both patient groups, $p<0.05$. (note: group contrasts conducted at MCCB domain level only, rather than for individual subtests) 


\section{Table 4}

Distribution of severity of impairment on MCCB overall composite score across groups

\begin{tabular}{|l|l|l|l|l|}
\hline $\begin{array}{l}\text { MCCB Overall Composite Score } \\
\text { Level of Impairment }\end{array}$ & $\begin{array}{l}\text { FESz } \\
\boldsymbol{n}\end{array}$ & $\begin{array}{l}\text { CSz } \\
\boldsymbol{n}\end{array}$ & $\begin{array}{l}\mathbf{N P} \\
\boldsymbol{n}\end{array}$ & $\begin{array}{l}\text { Total } \\
\boldsymbol{n}\end{array}$ \\
\hline Severe impairment (T<20) & $23^{a}$ & $42^{b}$ & 5 & 70 \\
\hline Moderate impairment (T=20-34) & $35^{a}$ & $75^{b}$ & 23 & 133 \\
\hline Mild impairment (T=35-39) & $16^{a}$ & 16 & 18 & 50 \\
\hline Below average (T=40-44) & 8 & 14 & 34 & 56 \\
\hline Unimpaired (T $₫ 45)$ & $17^{a}$ & $20^{b}$ & 209 & 246 \\
\hline Total & 99 & 167 & 289 & 555 \\
\hline$\chi^{2}(8)=240.46, p<0.01$ & & & \\
\hline
\end{tabular}

Note: FESz: first-episode schizophrenia, CSz: chronic schizophrenia, NP: non-psychiatric community comparison sample.

$a_{\mathrm{FESz}}$ differ from NP, $p<0.05$,

${ }^{b} \mathrm{CSz}$ differ from NP, $p<0.05$ (the two patient groups did not differ from each other). 